\title{
EFFECT OF PREHEATING AND DIFFERENT MOISTURE CONTENT OF INPUT MATERIALS ON DURABILITY OF PELLETS MADE FROM DIFFERENT PHYTOMASS CONTENT
}

\author{
Miroslav MACÁK ${ }^{* 1}$, Ladislav NOZDROVICKÝ1, Affan Othman HUSSEIN² \\ 'Slovak University of Agriculture in Nitra, Slovak Republic \\ ${ }^{2}$ Khabat Agricultural Technical Institute, Erbil, Iraq
}

\begin{abstract}
This paper analyses the effects of the storage process on the durability of pellets made of different types of biomass (lucerne hay, maize stover, wheat straw, miscanthus, prickly lettuce) for energy purposes. Pellets were produced on a hydraulic press that allowed modifying the size of pellets. The durability of pellets was measured on a special testing instrument according to the ASAE S269.4 (2007) standard method. The pellets used in the test were produced by pressing without preheating and with preheating. Durability rating was expressed as the ratio of the original mass of pellets and the mass of pellets remaining on a $17 \mathrm{~mm}$ opening sieve after tumbling. Storage negatively affected the durability of pellets made without preheating for all the types of biomass materials in different moisture contents. On the other hand, there was some positive response to storing of pellets made with preheating. The durability of pellets made of maize stover, wheat straw and miscanthus in the moisture content of $5 \%$ increased with storing.
\end{abstract}

Keywords: biomass, pelleting, durability test

Increasing concerns about climate change mitigation and rising oil prices are creating an unprecedented interest in the development of economical and convenient renewable energy fuels. Recent advances in biomass feedstock development and conversion technologies have created new opportunities for using agricultural land as a means of producing these renewable fuels in larger quantities than relying on wood and agricultural residues alone. Dedicated agricultural feedstocks such as wheat straw, maize stover, rape stover, switch grass, miscanthus, etc. and short rotation willow can abate with high quality petroleum running out in the next 50 years. World governments and the petrochemical industry alike are looking at biomass as a substitute refinery feedstock for liquid fuels and other bulk chemicals. New large plantations are being established in many countries, mostly in the tropics, but also in China, North America, Northern and Central Europe, and also in Russia (Samson et al., 2000). From a total energy use standpoint, however, biomass provides a relatively small percentage of the world's current energy needs. Most of the total energy use is found in more developed countries, not in regions with large populations. Biomass has the potential to provide a much greater share of the world's energy, particularly in the USA. Renewable biomass removes $\mathrm{CO}_{2}$ from the atmosphere for biomass production and then releases this $\mathrm{CO}_{2}$ back into the atmosphere when burned.

There are different methods of biomass processing for energy purposes. In last years, the pelleting of biomass has become the most used technology for processing of biomass. There are different systems of pellets manufacturing, but the efficiency of biomass using depends upon the type of biomass. Pellets are usually made of lucerne, miscanthus, maize stover, wheat straw, and prickly lettuce.

Lucerne pellets have been known to generate dust and fines because of repeated handling and transport. During transport, this product loses or gains moisture, which may affect its quality. Therefore, there is a need to manufacture pellets that are not prone to breakage but still can be palatable to animals. Tabil (1996) conducted an experiment to determine the effect of chop quality, process and machine variables on the quality of lucerne pellets. Three different qualities of lucerne chops, namely low, intermediate and high quality, were used in the experiment.

An experiment was conducted by Mani et al. (2004), where maize stover was compacted in a piston cylinder with three pressures, i.e. 5, 10, and $15 \mathrm{MPa}$, at three moisture content levels, i.e. 5,10 , and $15 \%(\mathrm{wb})$, to produce briquettes. The total energy requirement to compress and extrude briquette was in the range of $12-30 \mathrm{MJ.t}^{-1}$. The briquette density was in the range of $650-950 \mathrm{~kg}^{-3} \mathrm{~m}^{-3}$ increasing with pressure and biomass moisture. Moisture content and pressure had a significant effect on briquette density, durability and stability. Maize stover produced highly dense, more stable and durable briquettes at low moisture levels (5 \% and $10 \%$ ) rather than at high moisture level (15\%). 


\section{Material and methods}

The main aim of the work was to study the effect of the type of biomass on the durability of pellets. Lucerne hay, maize stover, wheat straw, miscanthus, and prickly lettuce have been used as crop material in the experiments focused on the study of effects of storage on the durability of pellets.

\section{Biomass processing and measured parameters}

All materials were chopped by using a manual straw chopper when they reached the desired moisture content. The chopper consisted of a drum holding in the inner side three cutting knives and a handle in the outer side. To obtain a coarser particle size of chops, two knives were removed and only one remained on the drum. The drum drives two feeding striated cylinders that regulate the feeding rate of the material to the cutters. A sample of $100 \mathrm{~g}$ of material was placed in a stack of sieves arranged from the largest to the smallest opening $(8,7$, $6,5,4,3,2$ and $1 \mathrm{~mm})$. The sieve series selected were based on the range of particles in the sample. The set of sieves was placed on the FRITSCH sieve shaker (Idar-Oberstein, Germany). The duration of sieving was 10 min, which was previously determined through trials to be optimal. This time duration was sufficient for all samples because of their fluffy and fibrous nature. After sieving, the mass retained on each sieve was weighed. Sieve analysis was repeated three times for each sample. The particle size was determined according to the ANSI/ASAE standard S424.1 (2008). The geometric mean diameter (x-gm) of samples and geometric standard deviation of particles (Sgm) was calculated according to the abovementioned standard.

The moisture content of a solid is defined as the quantity of water per unit mass of the wet solid. The moisture content of biomass materials is generally variable. The initial moisture content of the experimental material used in this work fluctuated between high and low, as we mentioned before, all materials stored in a warm room for reducing the initial moisture content.

The moisture content (MC) of raw materials was determined according to the ASAE standard S358.2 for forages (ASABE, 2008). Five grams of each chopped biomass species were weighted by using a digital scale balance with the nearest sensitivity of $0.001 \mathrm{~g}$ and placed inside the convection drying oven for 24 hours at $103 \pm 2{ }^{\circ} \mathrm{C}$ for moisture content measurement and repeated for three replicates. Moisture contents were expressed in percent wet basis (wb).

The bulk density of samples was measured using the grain bulk density apparatus. The sample was placed on the funnel and dropped at the centre of a 0.5 I steel cup continuously. Since the sample was fluffy and did not flow down readily through the funnel, it was stirred using a thin rod in order to maintain a continuous flow of the material. The cup was levelled gently from the excess amount by moving the steel rod in a zigzag pattern across the top of the cup. The mass within the cup was then weighed. Mass per unit volume gave the bulk density of the biomass in $\mathrm{kg} \cdot \mathrm{m}^{-3}$. Three replicates were performed for each feedstock (Mani et al., 2006). The unit density of pellets was determined by the direct measurement method according to the ASABE S269.4 (2007) standard. The volume of pellets was calculated by measuring the length and diameter of individual pellets by means of a digital Vernier calliper, and then pellets were weighted by the digital scale balance. Unit density was calculated as the ratio between the mass of pellets and its volume and expressed after conversion in $\mathrm{kg} \cdot \mathrm{m}^{-3}$. Measurements were done three times, and the average was recorded.
For the production of pellets, the hydraulic press was used.

\section{Measuring of durability of pellets}

In this study, the durability of pellets was measured according to the ASAE S269.4 (2007) standard method, which is intended to assess the durability of cubes, pellets and crumbles.

A sample of about five pellets was placed in a dust-tight box. The box was rotated about an axis, which was perpendicular to the box and centred in the $300 \mathrm{~mm}$ side. A $230 \mathrm{~mm}$ long baffle was affixed symmetrically and diagonally to inside the box $(300 \times$ 300) $\mathrm{mm}$. The samples were rotated for $10 \mathrm{~min}$ at $50 \mathrm{rpm}$. Figure 1 shows the durability test instrument, five pellets of each treatment were tested with three replications for the durability measurement. Durability rating was expressed as the ratio between the original mass of pellets and the mass of pellets remaining on a $17 \mathrm{~mm}$ opening sieve after tumbling, in accordance with the following equation:

$$
D_{p}=\frac{M_{p a t}}{M_{p b t}} \cdot 100
$$

where:

$D_{p} \quad$ - durability of pellets (\%)

$M_{p a t} \quad$ - mass of pellets after tumbling (g)

$M_{p b t}$ - mass of pellets before tumbling (g)

Normally, pellets will be tested immediately after cooling. When the temperature of pellets falls within $-5{ }^{\circ} \mathrm{C}$ of ambient, they are considered cool. If tested at a later time, the time,

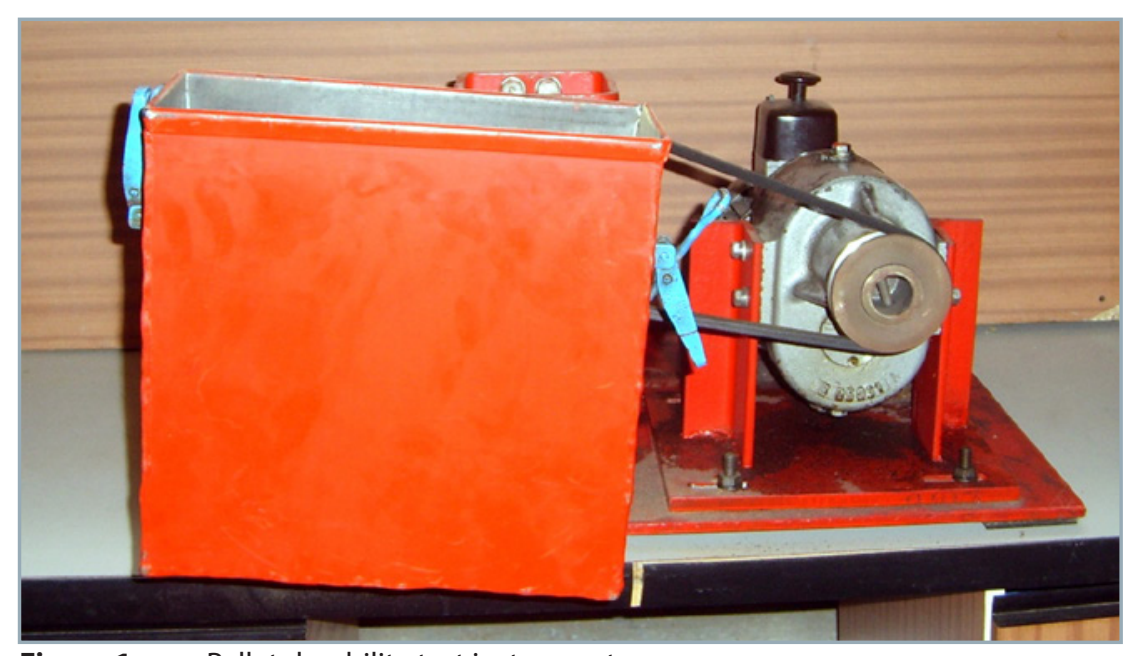

Figure 1 Pellet durability test instrument 
in hours after cooling, will be indicated as a subscript of durability. For example, if the tested durability of pellets is value 87 after two hours of cooling from the point of extruding, then the results will be expressed as $(87)_{2}$. If pellets are tested before cooling, there will be a significant weight loss caused by water vaporisation, and apparent durability will be decreased by this loss of water vapour. The loss of water vapour must be determined by making moisture content determinations before and after tumbling and compensating the final mass accordingly. When this procedure is followed, durability would be expressed as (95) . In this study, all pellets made with preheating were tested for durability after two hours of cooling from the point of extruding.

\section{Statistical analysis of experimental results}

All statistical analyses were performed using the software Statistica 10.0 at a $1 \%$ significance level. A completely randomized design (CRD), two-way (ANOVA), was used for analysing the pellets bulk density and durability. In the first way, moisture content represented the treatments and the biomass materials represented the replications. In the second way, the biomass materials represented the treatments and moisture content represented the replication. The least significant difference test (LSD) was used for comparing the means of different treatments. The paired $t$-test was used for comparing the means of the methods used for pelleting (preheating the die and without preheating) at the $1 \%$ significance level.

\section{Results and discussion}

Storage is considered an important indicator for selecting the production procedure of pellets with respect to their quality. Because pellets are not always used for their purpose immediately after producing, they must be stored for a certain period of time, and then they are exploited. Maintaining the pellets in a stable form and conserving their durability during the time of storing imposes high demands on production quality. The following results present the durability of pellets produced from different types of phytomass and stored for three weeks under a room temperature of $22{ }^{\circ} \mathrm{C}$ and $55 \%$ relative humidity.

\section{Lucerne hay pellets}

The effect of storage on the durability of lucerne hay pellets made with and without preheating, with different moisture contents, with their standard deviations are shown in Table 1. It was observed that storage negatively affected the reduction of the durability of lucerne pellets made without preheating for all moisture contents; however, statistically, it did not reach the level of significance, especially with the moisture content of $7 \%$ and $10 \%$ where it was $5 \%$ and $10 \%$ respectively. The greatest reduction was with the moisture content $20 \%$, which was about $37 \%$. It can be observed from the table that the storage of pellets affected the durability of preheated pellets with different moisture contents. The durability of pellets made from the material with the moisture content of $5 \%$ was lower by $14 \%$, whereas with the same moisture content without preheating, decrease was by only $5 \%$. With the moisture content of $20 \%$, there was a significant relationship $(P<0.01)$ in the durability of pellets made without preheating and the pellets made with preheating; reduction was by $3 \%$ without preheating and $37 \%$ with preheating.

\section{Prickly lettuce pellets}

Table 2 illustrates the durability of pellets before and after storage, produced with and without preheating, with different moisture contents and their standard deviations. It shows that the durability of pellets was deeply affected by storage, especially in the moisture contents of 10 , 15 and $20 \%$, where they were reduced by $23 \%, 13 \%$ and $13 \%$ respectively, whereas with the moisture content of $7 \%$, reduction was about $9 \%$. As for the durability of preheated pellets, it can be observed that storage enhanced the durability of pellets made with the moisture content of $10 \%$ where durability increased by $9 \%$. In other moisture contents, durability decreased. In the moisture content of $7 \%$, reduction was low and it was only $4 \%$, but the greatest reduction was for the moisture content of $15 \%$, i.e. by $31 \%$.

\section{Wheat straw pellets}

Pellets before and after storage were compared. Table 3 demonstrates the effect of storage on pellets made with and without preheating, with different moisture contents. It was observed that the durability of pellets made without preheating with the moisture content of $10 \%$ and $15 \%$ increased after storage by $3 \%$ and $17 \%$ respectively, whereas the durability of pellets made with the moisture content of $5 \%$ was reduced by $11 \%$. As for the wheat straw pellets made with preheating, basically their durability in moisture contents was not stable. The only moisture content at which produced pellets were mechanically

Table 1 Durability of lucerne hay pellets before and after storing produced with and without preheating with different moisture contents

\begin{tabular}{|l||c|c|c|c|}
\hline \multicolumn{1}{|l||}{$\begin{array}{l}\text { Biomass moisture } \\
\text { content in \% }\end{array}$} & \multicolumn{2}{c|}{$\begin{array}{c}\text { *Durability of pellets produced without } \\
\text { preheating in \% }\end{array}$} & \multicolumn{2}{c|}{$\begin{array}{c}\text { *Durability of pellets produced } \\
\text { with preheating in \% }\end{array}$} \\
\cline { 2 - 5 } & before storage & after storage & before storage & $73 \pm 1.9$ \\
\hline \hline $\mathbf{7}$ & $78 \pm 1.8$ & $73 \pm 1.7$ & $\#(87)_{2} \pm 1.9^{* *}$ & $73 \pm 2.1$ \\
\hline $\mathbf{1 0}$ & $75 \pm 1.6$ & $73 \pm 1.9$ & $(76)_{2} \pm 1.6$ & $74 \pm 1.6$ \\
\hline $\mathbf{1 5}$ & $53 \pm 1.7$ & $42 \pm 2.1$ & $(83)_{2} \pm 2.2$ & $67 \pm 1.8$ \\
\hline $\mathbf{2 0}$ & $50 \pm 1.9$ & $13 \pm 1.3$ & $(73)_{2} \pm 1.9$ & after storage \\
\hline
\end{tabular}


Table 2

Durability of prickly lettuce pellets before and after storage, produced with and without preheating, with different moisture contents

\begin{tabular}{|l||c|c|c|c|}
\hline \multicolumn{1}{|c||}{ Moisture content in \% } & \multicolumn{2}{c|}{$\begin{array}{c}\text { *Durability of pellets produced without } \\
\text { preheating in \% }\end{array}$} & \multicolumn{2}{c|}{$\begin{array}{c}\text { *Durability of pellets produced } \\
\text { with preheating in \% }\end{array}$} \\
\cline { 2 - 5 } & before storage & after storage & before storage & after storage \\
\hline \hline $\mathbf{7}$ & $66 \pm 1.3$ & $57 \pm 1.8$ & $\#(82)_{2} \pm 1.9 * *$ & $82 \pm 2.1$ \\
\hline $\mathbf{1 0}$ & $57 \pm 1.3$ & $34 \pm 1.6$ & $(73)_{2} \pm 2.1$ & $34 \pm 1.8$ \\
\hline $\mathbf{1 5}$ & $17 \pm 1.6$ & $4 \pm 1.2$ & $(65)_{2} \pm 1.6$ & $0 \pm 0.0$ \\
\hline $\mathbf{2 0}$ & $19 \pm 1.5$ & $6 \pm 1.1$ & $0 \pm 0.0$ & \\
\hline
\end{tabular}

* mean \pm standard deviation $(n=5)$; \# durability tested two hours after cooling; ** mean difference is significant at $\alpha=0.01$

Table 3 Durability of wheat straw pellets before and after storage, produced with and without preheating with different moisture contents

\begin{tabular}{|l||c|c|c|c|}
\hline \multicolumn{1}{|c||}{ Moisture content in \% } & \multicolumn{2}{c|}{$\begin{array}{c}\text { *Durability of pellets produced without } \\
\text { preheating in \% }\end{array}$} & \multicolumn{2}{c|}{$\begin{array}{c}\text { *Durability of pellets produced } \\
\text { with preheating in \% }\end{array}$} \\
\cline { 2 - 5 } & before storage & after storage & before storage & after storage \\
\hline \hline $\mathbf{5}$ & $86 \pm 2.3$ & $75 \pm 2.0$ & $\#(83)_{2} \pm 2.1$ & $89 \pm 2.4 * *$ \\
\hline $\mathbf{1 0}$ & $58 \pm 2.1$ & $61 \pm 1.9$ & $0 \pm 0.0$ & $0 \pm 0.0$ \\
\hline $\mathbf{1 5}$ & $38 \pm 1.6$ & $55 \pm 1.6$ & $0 \pm 0.0$ & $0 \pm 0.0$ \\
\hline $\mathbf{2 0}$ & $0 \pm 0.0$ & $0 \pm 0.0$ & $0 \pm 0.0$ & $0 \pm 0.0$ \\
\hline
\end{tabular}

* mean \pm standard deviation $(n=5)$; \# durability tested two hours after cooling; ${ }^{* *}$ mean difference is significant at $\alpha=0.01$

stable was $5 \%$. Measured durability increased by $6 \%$ compared with previous storing.

\section{Miscanthus pellets}

The mean durability of pellets made from miscanthus with different procedures is given in Table 4. The miscanthus pellets made without preheating were not stable in different pressing procedures and storage affected it negatively. Storage reduced the durability of miscanthus pellets made with the moisture content of $5 \%$ by $5 \%$, whereas the durability of pellets made with the moisture content of $10 \%$ did not change by storage. As for the miscanthus pellets made with preheating, there were variances between the pellets with the moisture content of $5 \%$ and $10 \%$. The durability of pellets with the moisture content of $5 \%$ increased by $26 \%$ as a result of storage, whereas the durability of pellets with the moisture content of $10 \%$ decreased by $14 \%$. Other moisture contents were not stable, as we mentioned before.

\section{Maize stover pellets}

Table 5 shows the effect of storage on the durability of maize stover pellets with and without preheating, with different moisture contents. It was observed that storage reduced the durability of pellets made without preheating for all moisture contents. The reduction of pellets made with the moisture content of $5 \%$ and $15 \%$ was $9 \%$ and $10 \%$ respectively. As for the pellets made with the moisture content of $10 \%$ and $20 \%$, reduction was low, reaching $4 \%$ and $1 \%$ respectively. Storage enhanced the durability of pellets made with preheating with the moisture content of $5 \%$ by $1 \%$, whereas it did not affect the durability of pellets made with the moisture content of $15 \%$ and stayed as it was. The pellets made with the moisture content of $10 \%$ slightly reduced their durability by $3 \%$ only, but the durability of pellets made with the moisture content of $20 \%$ decreased by $6 \%$.

Generally, storage did not affect strongly the pellets made from maize stover, especially those produced with preheating with different moisture contents. Furthermore,

Table 4 Durability of miscanthus pellets before and after storage, produced with and without preheating with different moisture contents

\begin{tabular}{|l||c|c|c|c|}
\hline \multirow{2}{*}{ Moisture content in \% } & \multicolumn{2}{c|}{$\begin{array}{c}\text { *Durability of pellets produced without } \\
\text { preheating in \% }\end{array}$} & \multicolumn{2}{c|}{$\begin{array}{c}\text { *Durability of pellets produced } \\
\text { with preheating in \% }\end{array}$} \\
\cline { 2 - 5 } & before storage & after storage & before storage & after storagea \\
\hline \hline $\mathbf{5}$ & $12 \pm 1.0$ & $7 \pm 1.1$ & & $\#(24) 2 \pm 1.1$ \\
\hline $\mathbf{1 0}$ & $4 \pm 0.4$ & $4 \pm 1.0$ & $(32) 2 \pm 1.3$ & $18 \pm 1.1$ \\
\hline $\mathbf{1 5}$ & $0 \pm 0.0$ & $0 \pm 0.0$ & $0 \pm 0.0$ & $0 \pm 0.0$ \\
\hline $\mathbf{2 0}$ & $0 \pm 0.0$ & $0 \pm 0.0$ & $0 \pm 0.0$ & $0 \pm 0.0$ \\
\hline
\end{tabular}


Table 5 Durability of maize stover pellets before and after storage, produced with and without preheating with different moisture contents

\begin{tabular}{|l||c|c|c|c|}
\hline \multirow{2}{*}{ Moisture content in \% } & \multicolumn{2}{c|}{$\begin{array}{c}\text { *Durability of pellets produced without } \\
\text { preheating in \% }\end{array}$} & \multicolumn{2}{c|}{$\begin{array}{c}\text { *Durability of pellets produced } \\
\text { with preheating in \% }\end{array}$} \\
\cline { 2 - 5 } & before storage & after storage & before storage & after storage \\
\hline \hline $\mathbf{5}$ & $88 \pm 1.9$ & $79 \pm 2.1$ & $\#(96)_{2} \pm 0.7$ & $97 \pm 0.3 * *$ \\
\hline $\mathbf{1 0}$ & $82 \pm 2.3$ & $78 \pm 1.8$ & $\#(94)_{2} \pm 0.6$ & $81 \pm 0.7$ \\
\hline $\mathbf{1 5}$ & $80 \pm 2.1$ & $70 \pm 1.9$ & $(84)_{2} \pm 2.3$ & $75 \pm 2.1$ \\
\hline $\mathbf{2 0}$ & $58 \pm 1.7$ & $57 \pm 1.5$ & $(81)_{2} \pm 1.2$ & $75 \pm 1.3$ \\
\hline
\end{tabular}

${ }^{*}$ mean \pm standard deviation $(n=5)$; \# durability tested two hours after cooling; ** mean difference is significant at $\alpha=0.01$

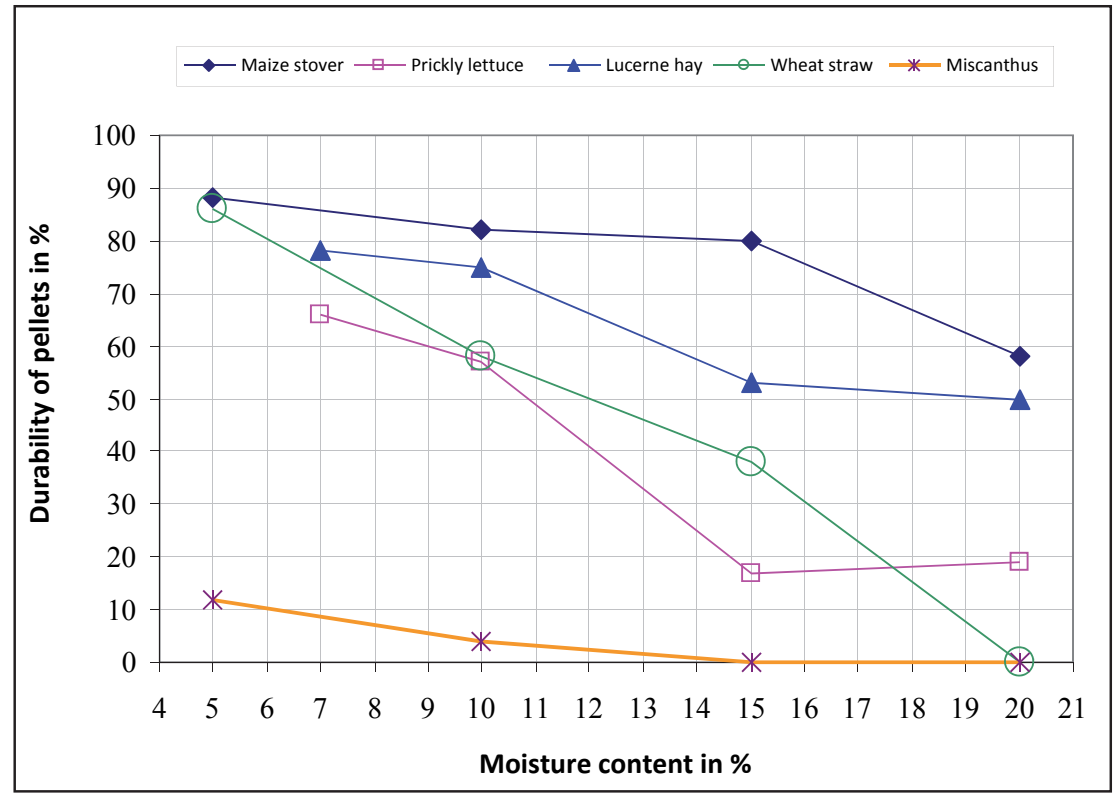

Figure 2 Durability of pellets made without preheating for all tested biomass materials

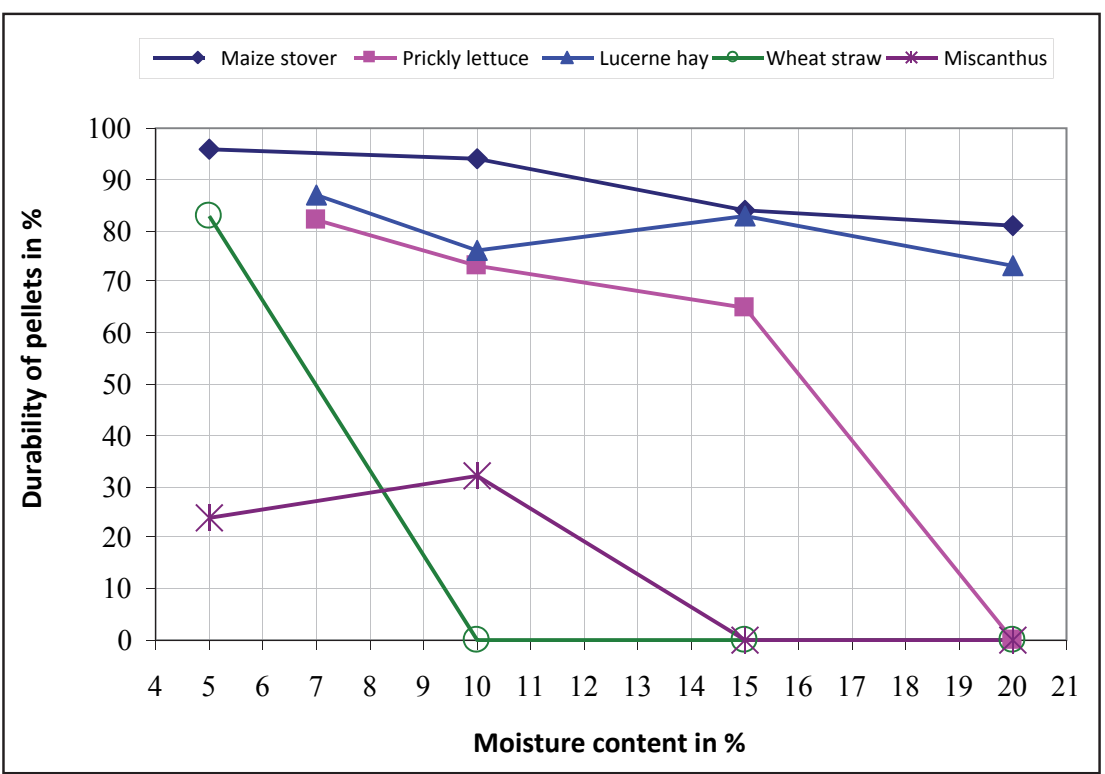

Figure 3 Durability of pellets made with preheating for all tested biomass materials storage enhanced the durability of pellets made with the $5 \%$ moisture content.

The effects of storing the pellets for three weeks under room temperature conditions for all biomass materials are expressed in the previous tables. Storage negatively affected the durability of pellets made without preheating for all the types of biomass materials in different moisture contents. On the other hand, there was some positive response to storage from pellets made with preheating. The durability of maize stover, wheat straw, and miscanthus pellets in the moisture content of $5 \%$ enhanced with storage. This enhancement might be due to gaining some moisture from the surrounding atmosphere. The water acts as a film type binder strengthening the bonding in pellets. Also, the water helps in promoting bonding by Van der Waals' forces, by increasing the true area of contact of particles. Fasina and Sokhansanj (1996) postulated that a small percentage of increase in moisture content (about $4 \%$ ) could have helped strengthen the bond between individual particles in the pellet due to binding forces of water molecules. Khoshtaghaza et al. (1999) found out that there is no effect on durability at low relative humidity levels (59-66\%).

The durability of pellets made without preheating from different biomass species in different moisture contents is given in Figure 2. It is obvious that moisture content affected negatively the durability of pellets made without preheating. Increasing the moisture content from $5 \%$ to $20 \%$ decreased the durability of biomass materials. This result disagreed with the results obtained by Andrejko and Grochowicz (2007), while it came in 
agreement with the results of Mani et al. (2006). They found that moisture content affected the durability of pellets. The storage for three weeks under room temperature conditions reduced the durability of all pellets in different moisture contents.

Figure 3 shows the durability of pellets made with preheating in different moisture content from all biomass materials. It can be observed that with elevating the moisture content, the durability of all biomass materials decreased, whereas durability increased for all biomass species when comparing with pellets made without preheating. Roughly all materials in the lowest moisture content $(5 \%)$ recorded the highest values of durability. This might be due to the fact that the water acts as a film type binder strengthening the bonding in pellets. Also, the water helps in promoting bonding by Van der Waals' forces, by increasing the true area of contact of particles. The right amount of moisture develops self-bonding properties in lignocelluloses substances at elevated temperatures and pressures prevalent in pelleting machines.

The value obtained from maize stover pellets durability was similar to the value obtained by Kaliyan (2008), but he mentioned that with preheating some losses in moisture content will occur during compaction due to the tolerance between the piston and cylinder wall. This loss of moisture content may effect on the compressibility of pellets. To preheat the biomass grinds, the bottom opening of the pelleting cylinder was closed tightly with a steel base that had an O-ring seal, the top opening of the cylinder was closed with a specially designed cap. He used maize stover with geometric mean particles of $0.8 \mathrm{~mm}$ in the moisture content of $10 \%$ and $15 \%$.

\section{Conclusion}

Using pellets from biomass for energy purposes is connected with a lot of problems. One of the problems to be solved is the durability of pellets when affected by storage. In order to increase the durability of pellets, it is necessary to find the right type of biomass, the composition of biomass and methods of biomass processing within the pellets production process. Testing the durability of biomass pellets in order to know the pellets quality can be considered an inseparable part of pellets quality research.

\section{Acknowledgements}

The research leading to the results presented in the paper has received funding from the European Community under the project no. 26220220180: Building the Research Centre 'AgroBioTech'.

\section{References}

ANDREJKO, D. - GROCHOWICZ, J. 2007. Effect of the moisture content on compression energy and strength characteristic of lupine briquettes. In Journal of Food Engineering, vol. 83, 2007, pp. 116-120.

ASAE Standards, 2001. S269.4: Cubes, pellets, and crumbles definitions and methods for determining density, durability, and moisture content. St. Joseph, Michigan : ASABE, 2001.

ASAE Standards, 2008. S424.1: Method of determining and expressing particle size of chopped forage materials by screening. St. Joseph, Michigan : ASABE, 2008.

ASAE Standards, 2008. S358.2: Moisture measurement - forages. St. Joseph, Michigan : ASABE, 2008.

FASINA, O.O. - SOKHANSANJ, S. 1996. Storage and handling characteristics of alfalfa pellets. In Powder Handling \& Processing, vol. 8, no. 4, pp. 361-365. (Cited by Kaliyan, 2008).

FRANKE, M. - REY, A. 2006. Pelleting quality. World Grain May 2006: 78-79.

KALIYAN, N. 2008. Densification of biomass. [Ph.D. Thesis]. Minnesota : University of Minnesota, 2008.

KHOSHTAGHAZA, M.H. - SOKHANSANJ, S. - GOSSEN, B.D. 1999. Quality of alfalfa cubes during shipping and storage. In Applied Engineering in Agriculture, vol. 15, 1999, no. 6, pp. 671-676.

MANI, S. - SOKHANSANJ, S. - BI, X. 2004b. Compaction of corn stover. ASAE paper number 041160 . St. Joseph, Michigan : ASABE, 2004.

MANI, S. - TABIL, G.L. - SOKHANSANJ, S. 2006a. Effects of compressive force, particle size and moisture content on mechanical properties of biomass pellets from grasses. In Biomass and Bioenergy, vol. 30, 2006, pp. 648-654.

SAMSON, R. - DUXBURY, P. - DRISDELLE, M. - LAPOINTE, C. 2000. Assessments of pelletized biofuels. [Retrieved 2007-01-14]. Retrieved from: http://www.reap-canada.com/online_library.pdf

STATISTICA 10.0, StatSoft, Inc., 2300 East $14^{\text {th }}$ Street, Tulsa, OK 74104.

TABIL, L. - SOKHANSANJ, S. 1996. Process conditions affecting the physical quality of alfalfa pellets. In Applied Engineering in Agriculture, vol. 12, 1996, no. 3, pp. 345-350. 